\title{
Metastasis of prostate gland adenocarcinoma to penile and scrotal cutaneous tissues
}

ROBERT L. FIORELLI, DO

LEONARD H. FINKELSTEIN, DO, FACOS

JOHN J. FERNANDES, DO, FACP, FASCP, FAOCPA

The metastatic sites of adenocarcinoma of the prostate are well documented. Bone metastasis is the most frequently encountered site. Skin metastasis is rarely reported. Its presence, however, is associated with a poor prognosis. The possible cause of cutaneous spread is discussed in the case report. The possible role that external-beam radiotherapy may play in this setting is also analyzed.

The route of metastasis of prostatic cancer is well known. Classically, there is lymphatic spread to regional inguinal nodes and, later, hematogenous spread to bone. Cutaneous metastasis is very rare; to date, only 30 cases have been reported in the literature. ${ }^{1}$
In this paper, we present a case in which previously irradiated, stage B2, grade I, well-differentiated adenocarcinoma of the prostate gland metastasized to penile and scrotal skin.

\section{Report of case}

Because of an abnormal prostatic gland discovered on digital rectal examination, a 73-year-old diabetic man had undergone transrectal needle biopsy in May 1984, when he was 70 years old. The procedure had revealed well-differentiated adenocarcinoma (Fig 1). At that time, serum acid phosphatase testing, computed tomography scanning of the pelvis, bone scanning, and pelvic lymphadenectomy findings were negative for metastasis.

The patient subsequently underwent external-beam radiation treatment to the prostate gland. Over a sixweek period, he received $4,860 \mathrm{rad}$ via box field to the pelvis and an additional 1,520 rad by rotational field,

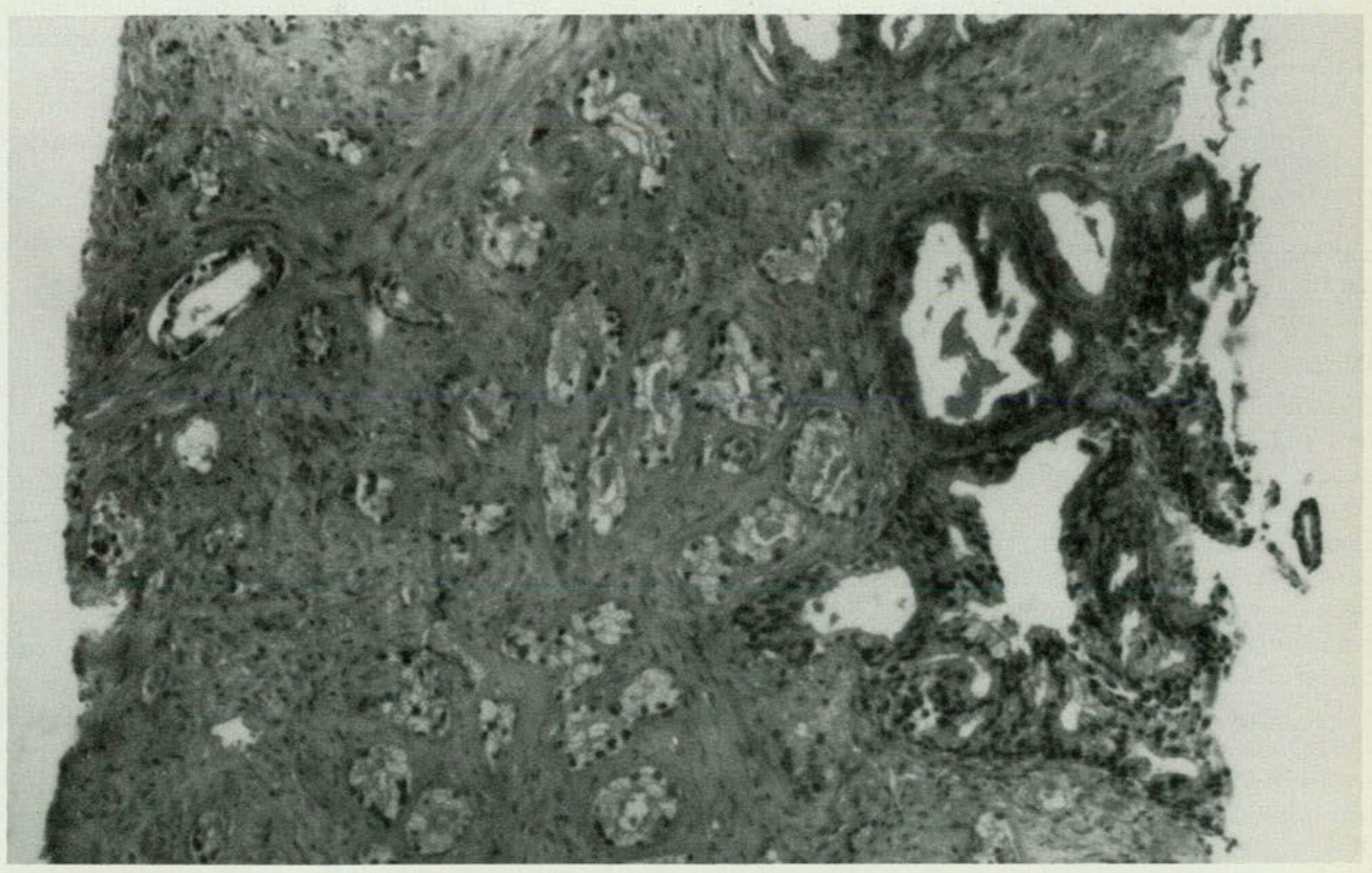

Fig 1. Multiple areas of clear cell adenocarcinoma, May 1984, (hematoxylin and eosin stain, original magnification $\times 100)$. 

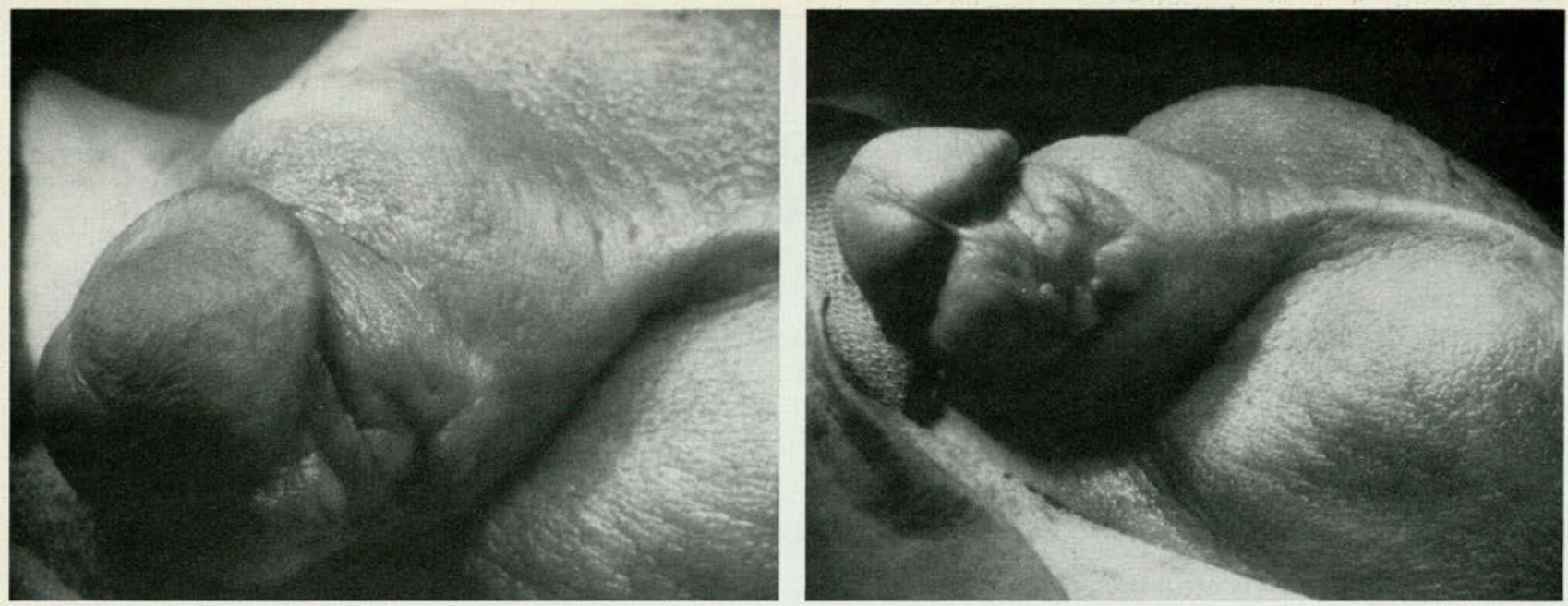

Figs 2, 3. Gross edema and normal skin color of the genitalia, without evidence of hyperpigmentation, May 1987.

for a total of 6,380 rad. Approximately four months after completion of radiation therapy, the patient noted increasing penile and scrotal edema, which caused difficulty in concealing the genitalia. After further progression of this condition (Figs 2, 3), the patient was admitted in May 1987 for penile scrotoplasty. Postoperatively, he did well, and an excellent cosmetic result was achieved.

Microscopic examination of the specimen revealed small islands of malignant cells in the dermal lymphatic channels (Fig 4). Immunoperoxidase stains were used, but a true-positive result was not obtained. Comparison of the malignant cells from the 1984 biopsy specimen and those from the dermal lymphatic channels confirmed the presence of prostatic adenocarcinoma in the penile and scrotal dermal tissue. If either serum study were elevated, the probability of metastasis would have certainly been more likely. It should be noted that yearly acid and alkaline phosphatase determinations have been normal to date.

\section{Discussion}

Cutaneous metastasis from prostatic carcinoma is a rare phenomenon. In Gates'2 1937 review of 2,298 autopsies, in only one of 58 cases of skin metastasis was prostatic carcinoma the primary tumor. Later, McCrea and Karafin ${ }^{3}$ were unable to demonstrate a single case of skin metastasis in 500 patients with prostatic cancer. A current review ${ }^{1}$ reveals only 30 prior cases of this unusual manifestation of prostatic carcinoma.

Our case is even more unusual, in that it is only the fifth reported case of skin metastasis following irradiation therapy. Katske and associates, ${ }^{4}$ who presented the fourth such case, suggested that radiation therapy did not contribute to the cutaneous metastasis, because of its very rarity. Other authors ${ }^{5-8}$ have demonstrated the efficacy of external-beam radiation therapy in localized prostatic cancer.

The development of lymphedema in our patient was most likely secondary to pelvic lymphadenectomy or radiation therapy, or both. The presence of chronic lymphedema following lymphadenectomy has been substantiated by Lieskovsky and associates. ${ }^{9}$ Pilepich and coauthors ${ }^{10}$ reported a $25 \%$ to $35 \%$ incidence of lymph dema in patients who underwent limited pelvic lymph adenectomy followed by radiation therapy. Other complications of therapy, such as deep-vein thrombosis, pulmonary embolism, urinary incontinence, hematuria, and gastrointestinal symptoms also have been recognized. However, our patient had no such problems. The main concern was one of cosmesis and concealment of his enlarged genitalia.

Another interesting point is that no other cutaneous manifestations of the disease were present. In all other reported cases, patients had visible evidence of various cutaneous abnormalities; these ranged from maculopapular discoloration over the involved skin regions to the appearance of acanthosis nigricans. ${ }^{11,12}$ Whether these metastatic nests of tumor cells are viable without the appearance of skin discoloration is not certain.

There have been many reports of unfavorable prognosis, with death occurring within one year of discovery of skin metastasis, regardless of whether the acid phosphatase level was within the normal range or elevated. ${ }^{11,12}$ Marquis and Benson ${ }^{13}$ have reported the longest survival time, with their patient living for 42 months after the appearance of skin metastasis. It may be that overt evidence of metastasis implies a poorer prognosis. In 
our case, it has been nearly two years since the identification of occult skin metastases, and the patient continues to do well.

The issue of the route of spread associated with cutaneous metastasis has been controversial. Originally, it was thought that a hematogenous route was likely. Schellhammer and colleagues ${ }^{14}$ were the first to propose this theory, which was based on their observations that their patients had other widespread metastases as well as the localized cutaneous component.

Recently, a lymphatic route has been thought to be the most plausible explanation for localized cutaneous metastasis. Marquis and Benson ${ }^{13} \mathrm{dem}$ onstrated by

lymphangiography that when central lymphatic obstruction was present, peripheral (cutaneous) collateralization was noted and subsequent skin metastasis occurred.

Pervaiz and coworkers ${ }^{12}$ postulated that in their patient, external-beam radiation caused lymphatic obstruction from fibrosis, which resulted in retrograde regurgitation of tumor emboli along cutaneous lymph channels and deposition of neoplastic cells in the dermis.

As has been stated, in our case immunoperoxidase staining had negative results. Tumor cells that produce prostatic acid phosphatase usually can be demonstrated by staining positively. However, Peterson ${ }^{15}$ and Allhoff and associates ${ }^{16}$ have shown that not all prostatic neoplasms uniformly react positively to this staining method in either primary or metastatic sites. We speculate that the patient's prior radiation therapy also may have contributed to the negative immunoperoxidase stain. Thus, as in other cases presented, the confirming evidence of prostatic adenocarcinoma in cutaneous tissue is based on the similar morphologic presentation of cell types and characteristics (Figs 1-4).

\section{Conclusions}

The presence of skin metastasis from prostatic carcinoma has been documented rarely. Certain factors, such as route and cause of metastasis, are poorly understood. Any form of distant cutaneous spread associated with other sites of metastasis most likely is by a hematogenous route, while local skin metastasis probably is via lymphatic channels.

It is plausible that radiation therapy has a direct relationship in causing cutaneous spread of fibrosing deep lymphatic tissue. This possible complication by no means precludes radiation therapy for localized prostatic carcinoma, but it is a stimu-

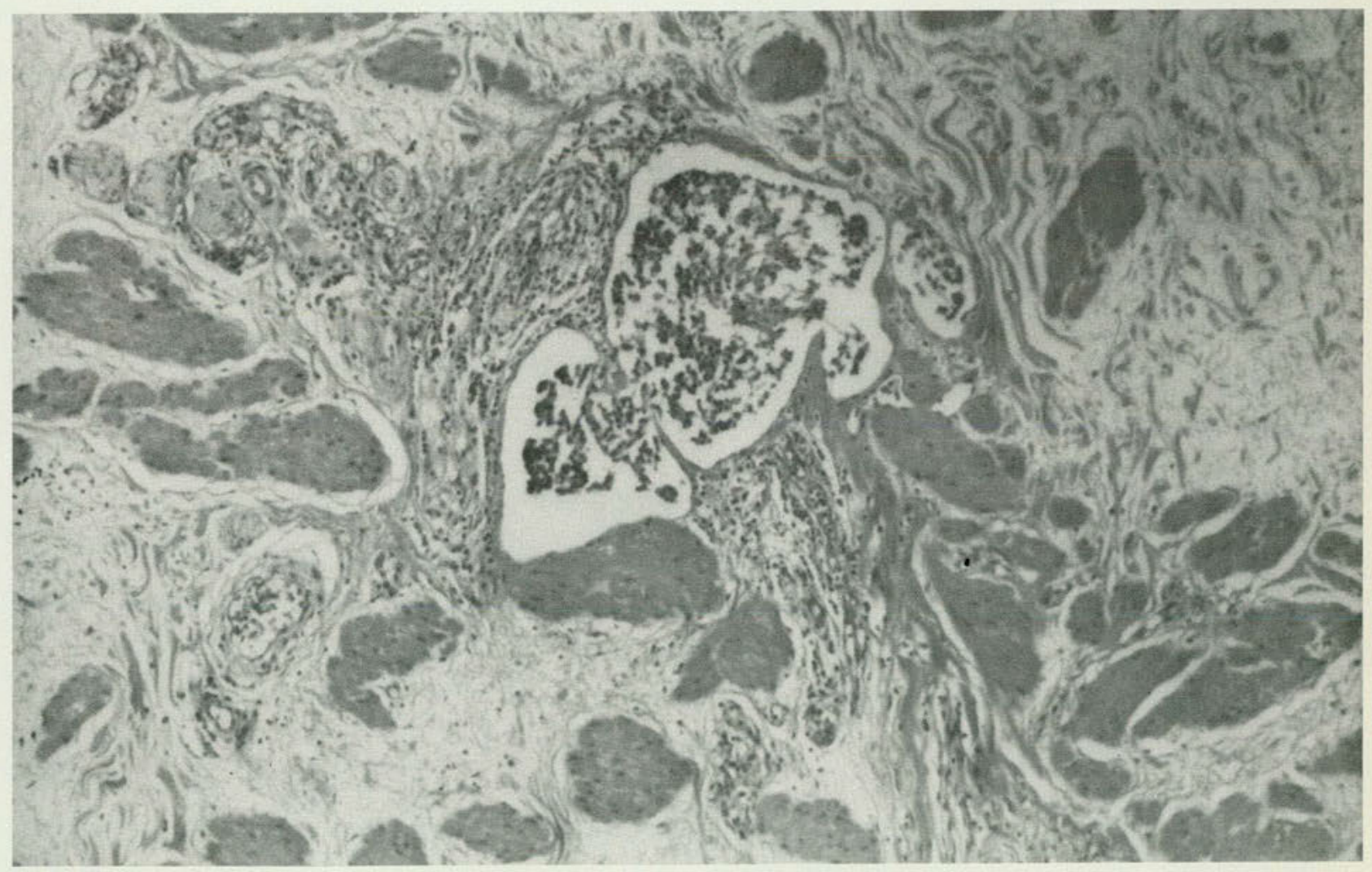

Fig 4. Nests of tumor cells in dermal lymphatic channels (hematoxylin and eosin stain, original magnification $\times 100$ ). 
lus to reassess our knowledge of prostatic cancer and its current treatment protocols and possible sequelae.

Finally, the presence of occult tumor nests in lymphedematous tissue perhaps should be considered in predicting prognosis in patients with apparently localized carcinoma of the prostate gland.

1. Kawashita E, Osumi Y, Nakamura K, et al: A case of prostatic carcinoma with skin metastases. Urol Int 1985;40:298-300.

2. Gates O: Cutaneous metastases of malignant disease. Am $J$ Cancer 1937;30:718-730.

3. McCrea LW, Karafin L: Carcinoma of the prostate: Metastases, therapy and survival: Statistical analysis of 500 cases. Int Coll Surg 1958;29:723-728.

4. Katske FA, Waisman J, Lupu AN: Cutaneous and subcutaneous metastases from carcinoma of prostate. Urology 1982;19:373-376.

5. Kurup P, Kramer TS, Lee MS, et al: External beam irradiation for prostate cancer: Experience in 163 patients. Cancer 1984;53:37-43.

6. Morton JD, Harrison LB, Peschel RE: Prostatic cancer therapy: Comparison of external-beam radiation and $\mathrm{I}-125$ seed implantation treatment of stages B and C neoplasms. Radiology 1986;159:249-252.

7. Leonard K, Stryker JA: Radiotherapy for prostate carcinoma. J Surg Oncol 1986;33:1-7.

8. Bagshaw MA, Ray GR, Cox RS: Radiotherapy of prostatic carcinoma: Long-or short-term efficacy (Stanford University experience). Urology 1985;25(suppl 2):17-23.
9. Lieskovsky G, Skinner DG, Weisenburger T: Pelvic lymphadenectomy in the management of carcinoma of the prostate. Urology 1980;124:635638.

10. Pilepich MV, Asbell SO, Mulholland GS, et al: Surgical staging in carcinoma of the prostate: Radiation Therapy Oncology Group experience. Prostate 1984;5:471-476.

11. Delima A, Mohamed A, Yalla SV, et al: Prostatic carcinoma metastasizing to skin and subcutaneous tissues. Urology 1973;2:663-665.

12. Pervaiz N, Fellner MJ, Davis JE: Cutaneous metastases from prostatic carcinoma. Urology 1978;11:403-405.

13. Marquis W, Benson R: Long-term survival with skin metastases from carcinoma of prostate. Urology 1980;16:407-408.

14. Schellhammer PF, Milstein R, Bunts RC: Prostatic carcinoma with cutaneous metastases. $\mathrm{Br} J$ Urol 1973;45:169-172.

15. Peterson RO, Stein B: Prostate, in Peterson RO (ed). Urologic Pathology Philadelphia, JB Lippincott Co, 1986, pp 594-598.

16. Allhoff EP, Proppe KH, Chapman CM, et al: Evaluation of prostate specific acid phosphatase and prostate specific antigen in identification of prostatic cancer. J Urol 1983;129:315-318.

From the Departments of Urology (Drs Fiorelli and Finkelstein) and Pathology (Dr Fernandes), Osteopathic Medical Center of Philadelphia.

Reprint request to Dr Fiorelli, 9200 Bustleton Ave, Apt 202, Alexander Bldg, Philadelphia, 19115. 


\section{The National Osteopathic Foundation Announces:}

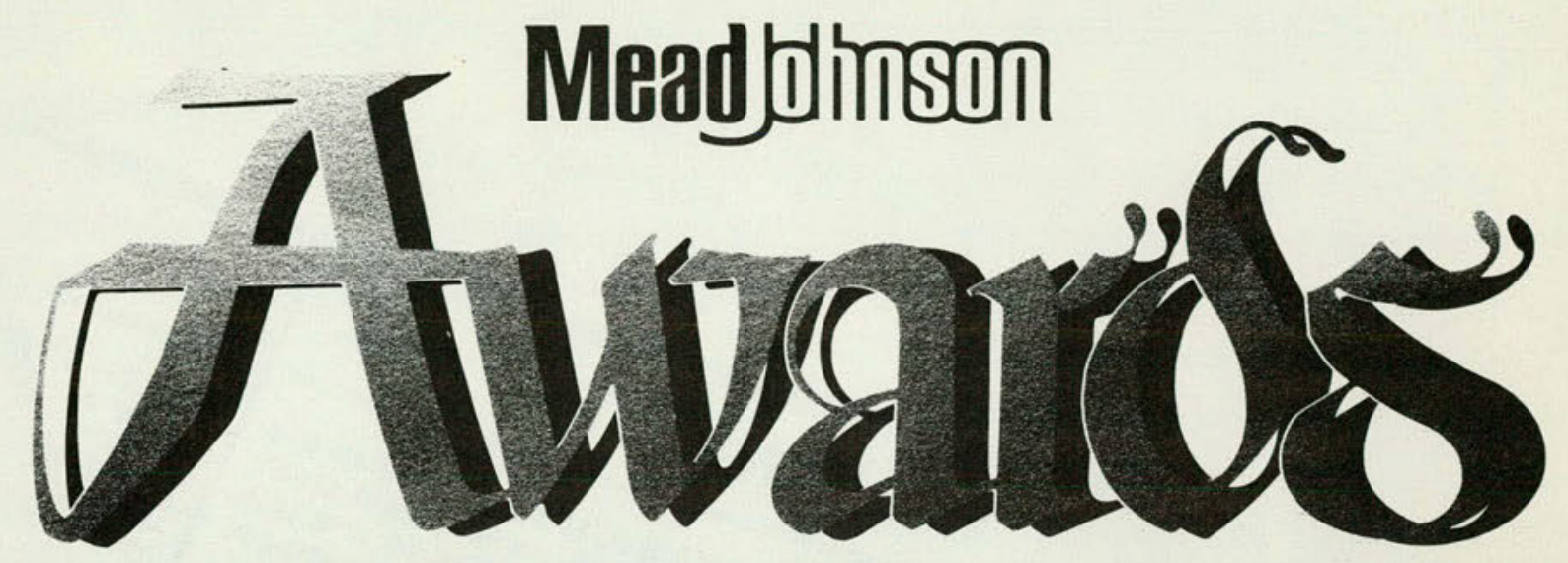

\section{FOR GRADUATE TRAINING}

Six $\$ 5,000$ awards in 1989 plus round trip transportation to AOA annual meeting

Award recipients will be the guests of honor at an awards breakfast to be hosted by Mead Johnson at the AOA Annual Meeting

- For residency training in AOA approved specialties

- The National Osteopathic Foundation administers all funds and selection of recipients

The Mead Johnson Awards for Graduate Training in osteopathic medicine provide financial assistance to selected graduates toward completion of a year of residency training. Mead Johnson has participated by providing funds for this joint endeavor since 1956.

Grants are available to any osteopathic physician within four years of date of graduation from an osteopathic college. The recipient may choose any hospital approved for residency training by the American Osteopathic Association.

Application forms may be obtained by writing to:

Committee on Educational Grants

The National Osteopathic Foundation 142 E. Ontario, 2nd Floor

Chicago, Illinois 60611

(800) 621-1773 (Ext. 5850)

FORMS MUST BE RETURNED BY APRIL 15, 1989 
